\title{
The Role of Productivity and Prices in Forecasting Wage Rates
}

\author{
Gary R. Albrecht and Kurt V. Krueger*
}

\section{Introduction}

In litigation involving wrongful death, personal injury and breach of employment contracts, forecasting the wage rate is often a necessary step when calculating damages. Forecasted future changes in the wage rate are generally attributed to two components, forecasted changes in the productivity of labor and inflation. ${ }^{1}$ The theoretical reason for making the wage rate a function of productivity and inflation stems from the neoclassical proposition that the wage rate is equal to the product of the marginal productivity of labor and the price of the output received by the manufacturer. So, when measures of productivity and inflation are used to justify a growth path for the future wage rate, they are proxy variables for, respectively, the marginal productivity of labor and changes in the price of the output.

This paper reviews the adequacy of the proxy variables commonly used for the marginal productivity of labor and the price of the output by checking to see if the characteristics of the proxy variables are similar to the characteristics of the subject variables. Based upon the sectors studied, we conclude that average productivity is not a good proxy variable for marginal productivity but, the rate of inflation is a good proxy for the change in the price of the output. Both of these conclusions have important implications for a forensic economist. First, changes in average productivity should not be used to justify changes in real wages. Second, the practice of forecasting real wages and discounting by a real interest rate is legitimate.

In Section II we explain the choice of subject variables and proxy variables used in the study. In Section III we compare the subject variables to the proxy variables and discuss the implications of the results. We present the conclusions in Section IV.

\section{The Subject and Proxy Variables}

Here we begin with the neoclassical level of the equilibrium wage rate, 1)

$$
\mathbf{w}_{\mathrm{t}}=\mathrm{mpl}_{\mathrm{t}} * \mathbf{p o}_{\mathrm{t}}
$$

\footnotetext{
* Gary R. Albrecht, Adjunct Associate Professor, Department of Economics, Wake Forest University and Consulting Economist for Economic Forecasting and Analysis Associates, Winston-Salem, NC; Kurt V. Krueger, Consulting Economist, Institute of Disability Appraisal, Overland Park, KS. Authors wish to thank Thomas Ireland and participants of the NAFE session at the 65th WEA International meetings for comments on this paper.

1 Authors who refer to "productivity" and "inflation" when discussing the growth path of future wages include: Albrecht and Moorhouse (1989), Brookshire and Smith (1990), Dillman (1988), Franz (1978), Lewis (1989), Marlin (1988), Pelaez (1989) and Schilling (1985).
} 
where:

$w_{t}$ is the wage rate in time $t$

$\mathrm{mpl}_{\mathrm{t}}$ is the marginal productivity of labor in time $\mathrm{t}$

$\mathrm{po}_{\mathrm{t}}$ is the price of the output received by the manufacturer in time $t$

Or, writing equation 1 ) as a rate of change ${ }^{2}$

$$
\begin{aligned}
\Delta \mathrm{w}_{\mathrm{t}} / \mathrm{w}_{\mathrm{t}-1}= & \Delta \mathrm{mpl}_{\mathrm{t}} / \mathrm{mpl}_{\mathrm{t}-1}+\Delta \mathrm{po}_{\mathrm{t}} / \mathrm{po}_{\mathrm{t}-1} \\
& +\left(\Delta \mathrm{mpl}_{\mathrm{t}} / \mathrm{mpl}_{\mathrm{t}-1}\right) *\left(\Delta \mathrm{po}_{\mathrm{t}} / \mathrm{po}_{\mathrm{t}-1}\right)
\end{aligned}
$$

rewriting 2) with obvious notation,

$$
\% \Delta \mathrm{w}_{\mathrm{t}}=\% \Delta \mathrm{mpl}_{\mathrm{t}}+\% \Delta \mathrm{po}_{\mathrm{t}}+\% \Delta \mathrm{mpl}_{\mathrm{t}} * \% \Delta \mathrm{po}_{\mathrm{t}}
$$

The general framework of equation 2) (2') for forecasting industry-wide changes in wages permeates the forensic economic literature. (Our concern in this paper is changes in wages that occur industry-wide. We do not consider changes in an individual's productivity and wages due to changes in individual circumstances, such as age, in this paper.) The acceptance of the framework is shown whenever the growth rate of wages is discussed in terms of the sum of the growth rate of productivity and inflation; this includes the debate on what real interest rate to use as the cancellation of prices in wage increases and interest rates relies upon this framework (see Albrecht and Moorhouse (1989)).

Forensic economists have used the average productivity of labor (output per hour of labor input) as a proxy for the marginal productivity of labor and inflation as a proxy for the growth rate of the output price. The question which naturally arises is whether these proxy variables are appropriate in the sense of having similar expected growth paths.

\section{A. Subject and Proxy Variables for the Marginal Product of Labor}

For a priori reasons the average productivity of labor may not be a desirable proxy for the marginal productivity of labor. If, for example, there were a capitalusing technological change so that the marginal product of capital increased relative to the marginal product of labor at a given capital-labor ratio, the marginal productivity of labor would decline and the average productivity of labor would increase at that capital-labor ratio; the subject variable and the proxy variable would move in opposite directions. Movement along a given capitallabor isoquant would, however, result in average and marginal productivity moving in the same direction. So, a priori we are not certain of the relative behavior of average and marginal productivity.

Another measure of productivity, which is reported by the federal government for certain sectors, is multifactor productivity. The multifactor productivity growth rate is equal to the growth rate of the average productivity of labor adjusted for the change in capital per hour (capital intensity) to output. In other words, multifactor productivity indicates the changes in output resulting from shifts of

\footnotetext{
${ }^{2}$ Since the data we will work with are discrete we do not take the derivative of equation 1) with respect to time but rather use the symbols for discrete change and recognize the interaction term. This choice makes no substantive difference.
} 
the production function as opposed to movements along the production function. ${ }^{3}$ This measure may reflect more accurately changes in the skill and effort of the work force.

The subject variable, the marginal productivity of labor, is not measured by a federal agency for any industry. By rearranging equation 1) we derive an equation for marginal productivity. Rearranging gives,

$$
\mathrm{mpl}_{\mathrm{t}}=\mathrm{w}_{\mathrm{t}} / \mathrm{po}_{\mathrm{t}}
$$

or, in terms of rate of growth

$$
\Delta \mathrm{mpl}_{\mathrm{t}} / \mathrm{mpl}_{\mathrm{t}-1}=\left(\left(\Delta \mathrm{w}_{\mathrm{t}} / \mathrm{w}_{\mathrm{t}-1}\right)-\left(\Delta \mathrm{po}_{\mathrm{t}} / \mathrm{po}_{\mathrm{t}-1}\right)\right) /\left(1+\left(\Delta \mathrm{po}_{\mathrm{t}} / \mathrm{po}_{\mathrm{t}-1}\right)\right)
$$

or

$$
\% \Delta \mathrm{mpl}_{\mathrm{t}}=\left(\% \Delta \mathrm{w}_{\mathrm{t}}-\% \Delta \mathrm{po}_{\mathrm{t}}\right) /\left(1+\% \Delta \mathrm{po}_{\mathrm{t}}\right)
$$

As data for $\mathrm{w}_{t}$ and $\mathrm{po}_{\mathrm{t}}$ exist, we can perform this arithmetic to develop a historical series for the marginal productivity of labor. The wage data we use in this study are hourly wages as opposed to hourly compensation which include benefits. Benefits are to a large extent a fixed cost to the firm of an individual employee but the meaning of $w_{t}$ in equation 1 ) is the marginal cost of labor.

\section{B. Subject and Proxy Variables for the Price of the Output}

In the application of equation 2$\left.)\left(2^{\prime}\right)\right)$ in forensic economics the inflation rate is commonly used as a proxy for the rate of growth of the price of the output. This is known to be a common practice because whenever the real rate of interest is used in the discounting process, the rate of inflation is being used as a proxy variable for the rate of growth of the output price; thus the cancellation of inflation in the wage rate growth and interest rate. The assumption implicit here is that the rate of growth of the output price will be equal to the inflation rate.

We use the Producer Price Index (PPI) for the sector to measure the price that the manufacturer receives for the output. And, we use the Consumer Price Index (CPI) to measure inflation.

\section{Comparison Results}

We check the legitimacy of using average productivity and multifactor productivity as proxy variables for marginal productivity and of using inflation as a proxy for the price of the output by comparing their historical behavior. The comparison includes the calculation of the historical mean of the rate of change of the subject and proxy variables. Then, using tests of statistical significance, we form an opinion as to whether the historical sample mean of the rate of change of the proxy variable can be considered to be the mean of the rate of change of the subject variable and, whether the two populations can be considered to have the same mean. The first test, whether the mean rate of change of the subject variable is equal to the historical sample mean of the rate of change of the proxy

\footnotetext{
${ }^{3}$ For a technical explanation of the multifactor productivity index see Mark and Waldorf (1983).
} 
variable, is relevant when the forensic economist desires to use the historical sample mean rate of change of the proxy variable as the forecast of the subject variable. This method of forecasting is legitimate when the series are stationary (there are no long-term trends in the series), when it is assumed that there will be no structural shifts, and, when it is accepted that the mean of the subject variable is the sample mean of the proxy variable. Also we check if the population means are equal. If the population means are not equal the estimate of the mean of the proxy variable should not be used as the estimate of the mean of the subject variable. Finally, we consider the correlation between the proxy and subject variable. The correlation would be of interest if a forecast of the path of the growth were desired. This section will illustrate, by using three specific sectors, how the comparisons may be made.

The three sectors we used are steel (SIC 331), motor vehicles and equipment (SIC 371), and manufacturing. The three-digit sectors were chosen based upon the availability of the multifactor productivity index. The multifactor productivity index project for three-digit sectors began recently and the data were first made available for SIC 331 and SIC 371. The data used in the study are annual from 1958 through 1987 . The years used are dictated by the availability of the multifactor productivity index. The PPI, wage rate, average productivity index and multifactor productivity index for each sector and the CPI are reported by the Bureau of Labor Statistics.

\section{A. Table 1}

Table 1 contains the mean of the actual growth rate of wages and the mean of the growth rates of wages which are calculated using proxy variables. The equations which were used to calculate the percent change in wages corresponding to the columns of Table 1 are:

6) $\quad \% \Delta \mathrm{w}_{\mathrm{t}}=\% \Delta \mathrm{mfp}_{\mathrm{t}}+\% \Delta \mathrm{CPI}_{\mathrm{t}}+\% \Delta \mathrm{mfp}_{\mathrm{t}} \cdot \% \Delta \mathrm{CPI}_{\mathrm{t}}$

8)

$$
\% \Delta \mathrm{w}_{\mathrm{t}}=\% \Delta \mathrm{apl}_{\mathrm{t}}+\% \Delta \mathrm{PPI}_{\mathrm{t}}+\% \Delta \mathrm{apl}_{\mathrm{t}} * \% \Delta \mathrm{PPI}_{\mathrm{t}}
$$

where:

$$
\% \Delta \mathbf{w}_{\mathrm{t}}=\% \Delta \mathrm{mfp}_{\mathrm{t}}+\% \Delta \mathrm{PPI}_{\mathrm{t}}+\% \Delta \mathrm{mfp}_{\mathrm{t}} \cdot \% \Delta \mathrm{PPI}_{\mathrm{t}}
$$

$\% \Delta \mathrm{w}_{\mathrm{t}}$ is the percent change of wages in the particular sector in time $\mathrm{t}$, $\% \Delta \mathbf{a p l}_{\mathrm{t}}$ is the percent change in the average productivity of labor in the particular sector in time $t$,

$\% \Delta \mathrm{CPI}_{\mathrm{t}}$ is the inflation rate in time $t$,

$\% \Delta \mathrm{mfp}_{\mathrm{t}}$ is the percent change in multifactor productivity in the particular sector in time $t$, and,

\% $\triangle \mathrm{PPI}_{\mathrm{t}}$ is the percent change in the PPI in the particular sector in time $\mathrm{t}$

From Table 1 we see that the mean of the percent change of actual wages over the period from 1958 to 1987 in the manufacturing sector is 5.52 . This amount is 231 basis points lower than the mean of the percent change in wages when calculated by using the average productivity and the CPI, 7.83. The difference 
Table 1

Statistics on Percent Change in Wages 1958-1987

Calculated by Using

\begin{tabular}{|c|c|c|c|c|c|}
\hline & $\begin{array}{l}\text { Actual } \\
\text { Wage } \\
\text { Data }\end{array}$ & $\begin{array}{l}\text { Average } \\
\text { Productiv- } \\
\text { ity and } \\
\text { CPI (equa- } \\
\text { tion 5) }\end{array}$ & $\begin{array}{l}\text { Multi- } \\
\text { factor } \\
\text { Productiv- } \\
\text { ity and } \\
\text { CPI (equa- } \\
\text { tion6) }\end{array}$ & $\begin{array}{c}\text { Average } \\
\text { Productiv- } \\
\text { ity and } \\
\text { PPI 371 } \\
\text { (equation 7) }\end{array}$ & $\begin{array}{c}\text { Multi- } \\
\text { factor } \\
\text { Productiv } \\
\text { ity and } \\
\text { PPI } 371 \\
\text { (equation } \\
8 \text { ) }\end{array}$ \\
\hline \multicolumn{6}{|l|}{ Manufacturing Sector } \\
\hline $\begin{array}{l}\text { Mean of Percent Change } \\
\text { Correlation With Actual }\end{array}$ & $\begin{array}{l}5.52 \\
1.0\end{array}$ & $\begin{array}{r}7.83^{\mathrm{ab}} \\
.587^{\mathrm{c}}\end{array}$ & $\begin{array}{r}7.06^{\mathrm{ab}} \\
.590^{\mathrm{c}}\end{array}$ & $\begin{array}{r}7.78^{\mathrm{ab}} \\
.590^{\mathrm{c}}\end{array}$ & $\begin{array}{r}7.01^{\mathrm{ab}} \\
.591^{\mathrm{c}}\end{array}$ \\
\hline \multicolumn{6}{|l|}{ SIC 331} \\
\hline $\begin{array}{l}\text { Mean of Percent Change } \\
\text { Correlation With Actual }\end{array}$ & $\begin{array}{l}5.61 \\
1.0\end{array}$ & $\begin{array}{c}8.14^{\mathrm{a}} \\
-.073\end{array}$ & $\begin{array}{c}6.83 \\
.047\end{array}$ & $\begin{array}{r}8.22^{\mathrm{a}} \\
-.073\end{array}$ & $\begin{array}{c}6.95 \\
.067\end{array}$ \\
\hline \multicolumn{6}{|l|}{ SIC 371} \\
\hline $\begin{array}{l}\text { Mean of Percent Change } \\
\text { Correlation With Actual }\end{array}$ & $\begin{array}{l}5.83 \\
1.0\end{array}$ & $\begin{array}{c}8.71^{\mathrm{ab}} \\
.295\end{array}$ & $\begin{array}{l}6.58 \\
.286\end{array}$ & $\begin{array}{c}8.63^{\text {ab }} \\
.297\end{array}$ & $\begin{array}{c}6.53 \\
2.88\end{array}$ \\
\hline
\end{tabular}

- Reject the null hypothesis that the mean of the percent change of the actual series is this number in a two-tailed $t$-test at the .05 level of significance.

${ }^{b}$ Reject the null hypothesis that the mean of percent change of this series is equal to the mean of percent change of actual wage in a two-tailed t-test at the .05 level of significance.

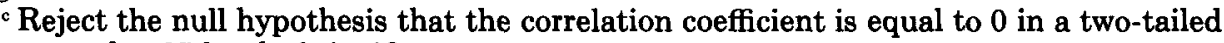
$t$-test at the .05 level of significance.

between the two numbers is such that we would reject the null hypothesis that the mean of the percent change of actual wages is 7.83 using a two-tailed t-test at the .05 level of significance; it would not be reasonable to contend that the mean of the percent change of actual wages is 7.83 . We reject the possibility of using 7.83 as the forecast of the future mean of the percent change of actual wages in the manufacturing sector. Further, the difference between the population means of the two series is statistically different than zero at a .05 level of significance. The fact that the population means of the two series are statistically different implies that a forecast for the percent change in wages in manufacturing based upon a forecast of the average productivity of labor in manufacturing and a forecast of the CPI would not be a logical forecast of the actual percent change in wages.

For the other methods of calculating the percent changes in wages in the manufacturing sector the results are the same as when the average productivity and CPI are used. We reject the hypothesis that the mean of the percent change of the actual wages is equal to the sample mean of the percent change of the other methods. And, the difference between the mean of the actual percent change in wages and the mean of the percent change when calculated by the other methods is significantly different at the .05 level.

Also in the manufacturing sector, we see that the correlation between the actual percent change in wages and the percent change in wages when calculated by using the average productivity and the CPI is .587. This degree of correlation 
is statistically different than zero at the .05 level of significance. So, although the two series have different means, they do move together to some extent.

Remaining on Table 1 but moving to the steel sector (SIC 331), we reject the null hypothesis that the mean of the actual percent change in wages is equal to the sample mean of the percent change in wages when calculated by using the average productivity of labor and the CPI. But, we accept the null hypothesis that the mean of the percent change of actual wages is equal to the mean of the percent change of wages calculated by using average productivity and the CPI. Similar conclusions are reached when average productivity and the PPI are used for the calculation. When multifactor productivity is used in the calculations, the null hypotheses concerning the value of the mean are accepted. We accept the null hypothesis that the correlation statistic is equal to zero.

The final sector considered on Table 1 is motor vehicles and parts (SIC 371). The results for this sector are similar to SIC 331 except that for SIC 371 we reject the null hypotheses that the means of the populations are equal.

In Table 1 the null hypotheses concerning the level of the mean of the percent change in wages are rejected several times. In Table 2 the percent change in wages is broken down into its components of productivity changes and price changes. This breakdown will allow us to determine more precisely the reason for the rejection of the null hypotheses.

\section{B. Table 2}

Table 2 reports the mean percent change in the productivity measures and the price measures. In the manufacturing sector, the mean of percent change in the marginal productivity of labor is 1.18 . (The marginal productivity series is calculated by using equation $4^{\prime}$ ).) The mean of percent change in average productivity in this sector is 2.85 . We reject the null hypothesis that the mean of percent change of marginal productivity is equal to 2.85 . However, we accept the null hypothesis that the mean of percent change in marginal productivity is equal to the mean of percent change of multifactor productivity. We accept the null hypotheses concerning the relationship between marginal productivity and multifactor productivity. For the other two sectors, SIC 331 and SIC 371, the relationships among the measures of productivity are the same as for the manufacturing sector; we reject the null hypothesis that the mean of the percent change in marginal productivity is equal to the historical sample mean of the percent change in average productivity but we accept the other null hypotheses. The movement of the measures of productivity are, in general, related (in SIC 331 the relationship is negative where significant).

With respect to the mean of percent change in prices, in each sector we accept both null hypotheses: the mean percent change in PPI is equal to the sample mean of the percent change in CPI and, the mean percent change in the PPI is the same as the mean percent change in the CPI. Further, in all three sectors the PPI has moved with the CPI.

\section{Implications of Comparison}

In none of the sectors considered in this paper can we appropriately use the sample mean of the percent change of wages calculated with average productivity 
Table 2

Statistics on Percent Change in Productivity and Prices 1958-1987

\begin{tabular}{|c|c|c|c|c|c|}
\hline & $\begin{array}{c}\text { Marginal } \\
\text { Produc- } \\
\text { tivity }\end{array}$ & $\begin{array}{c}\text { Average } \\
\text { Produc- } \\
\text { tivity }\end{array}$ & $\begin{array}{c}\text { Multi- } \\
\text { factor } \\
\text { Produc- } \\
\text { tivity }\end{array}$ & PPI & CPI \\
\hline \multicolumn{6}{|l|}{ Manufacturing Sector } \\
\hline $\begin{array}{l}\text { Mean of Percent Change } \\
\text { Correlation With Actual }\end{array}$ & $\begin{array}{l}1.18 \\
1.0\end{array}$ & $\begin{array}{c}2.85^{\mathrm{a}} \\
.481^{\mathrm{c}}\end{array}$ & $\begin{array}{l}2.12 \\
.562^{c}\end{array}$ & $\begin{array}{l}4.47 \\
1.0\end{array}$ & $\begin{array}{l}4.89 \\
.914^{\circ}\end{array}$ \\
\hline \multicolumn{6}{|l|}{ SIC 331} \\
\hline $\begin{array}{l}\text { Mean of Percent Change } \\
\text { Correlation With Actual }\end{array}$ & $\begin{array}{l}.82 \\
1.0\end{array}$ & $\begin{array}{c}3.18^{\mathrm{a}} \\
-.303\end{array}$ & $\begin{array}{l}1.90 \\
-.436^{c}\end{array}$ & $\begin{array}{l}5.02 \\
1.0\end{array}$ & $\begin{array}{l}4.89 \\
.648^{\circ}\end{array}$ \\
\hline \multicolumn{6}{|l|}{ SIC 371} \\
\hline $\begin{array}{l}\text { Mean of Percent Change } \\
\text { Correlation With Actual }\end{array}$ & $\begin{array}{l}2.15 \\
1.0\end{array}$ & $\begin{array}{l}3.73^{\mathrm{a}} \\
.488^{\mathrm{c}}\end{array}$ & $\begin{array}{l}1.68 \\
.466^{\mathrm{c}}\end{array}$ & $\begin{array}{l}3.69 \\
1.0\end{array}$ & $\begin{array}{l}4.89 \\
.912^{\circ}\end{array}$ \\
\hline
\end{tabular}

a Reject the null hypothesis that the mean of the percent change of the actual series is this number in a two-tailed $t$-test at the .05 level of significance.

${ }^{b}$ Reject the null hypothesis that the mean of percent change of this series is equal to the mean of percent change of actual wage in a two-tailed $t$-test at the .05 level of significance.

${ }^{c}$ Reject the null hypothesis that the correlation coefficient is equal to 0 in a two-tailed t-test at the .05 level of significance.

as the mean of the actual percent change in wages. Thus, even if it is assumed that the generating process is stationary (a questionable assumption judging from the autocorrelations), the sample mean of the percent change of wages of the series calculated by using average productivity should not be used as a forecast of the mean of percent change in actual wages. Also, in each sector, comparing the mean of percent change of average productivity to the mean of percent change of marginal productivity reveals that the sample mean of average productivity is not the mean of the percent change of marginal productivity. This is an important result because it means that for these sectors there is no justification for using the sample mean of average productivity as a forecast of marginal productivity.

Multifactor productivity performed better than average productivity when used in the calculation of the percent change in wages and when compared directly to marginal productivity. In two of the three sectors it would be justifiable to use multifactor productivity in lieu of marginal productivity.

In each sector the mean of the percent change in the PPI can be estimated using the sample mean of the percent change in the CPI. And, in each sector the means of the percent change in the PPI can be considered to be the same as the mean of the percent change of the CPI. The movement of the individual PPI is highly correlated with the movement of the CPI. These results have important ramifications for the forensic economist. When calculating the present value of a future wage it is common in forensic economics to multiply the current wage by productivity (a real growth factor) and divide the product by the real interest rate. The reasoning is, of course, that the inflation factor which affects the increase in wages cancels out with the inflation factor in interest rates. This cancellation 
is only valid when the economist can contend that the future percent change of the price of the particular sector is the same as the future percent change of the overall price index. Also, the contention that future changes in real wages will be equal to changes in productivity implies the contention that the future changes in the price of the output and inflation are the same.

\section{Conclusions}

The justification for referring to the productivity of labor when estimating future growth rates of labor presumably stems from the neoclassical explanation for the level of wage rates. The productivity in the neoclassical explanation is of course the marginal productivity of labor. In forensic economic applications average productivity is sometimes used as a proxy for marginal productivity and overall price indices are used as proxies for the price the manufacturer receives for the output.

In this paper we studied three sectors in order to check the legitimacy of using average productivity and multifactor productivity as proxies for marginal productivity and using the rate of inflation as a proxy for the rate of change in the price of the output. We conclude that average productivity is not a good proxy for marginal productivity, that multifactor productivity serves as a better proxy average productivity and, that inflation is a good proxy for the price of the output. For these sectors the use of inflation as a proxy is legitimate and thus the common practice of using the real growth rate of wages and the real interest rate is reasonable.

The overriding message from the study is that it should not be assumed that average productivity is a good proxy for marginal productivity. It is thus necessary to confirm, using historical data, that average productivity can be used as a proxy for marginal productivity. This confirmation process requires the calculation of the historical marginal productivity series. However, once one has calculated the historical marginal productivity series there is every reason to use the series to forecast marginal productivity rather than using the historical average productivity series as a proxy for the historical marginal productivity series.

\section{References}

Albrecht, Gary R. and John C. Moorhouse, "On the Derivation and Consistent Use of Growth and Discount Rates for Future Earnings," Journal of Forensic Economics, August 1989, 2(3), 95-102.

Brookshire, Michael L. and Stan V. Smith, Economic/Hedonic Damages: The Practice Book for Plaintiff and Defense Attorneys, Cincinnati: Anderson Publishing Co., 1990.

Dillman, Everett G., "The Age-Earnings Cycle-Earnings by Education," Journal of Forensic Economics, December 1988, 2(1), 105-116.

Franz, Wolfgang W., "A Solution to Problems Arising From Inflation When Determining Damages," Journal of Risk and Insurance, June 1978, 323-333.

Lewis, Cris W., "On the Relationship Between Age, Earnings and the Net Discount Rate," Journal of Forensic Economics, August 1989, 2(3), 69-78.

Mark, Jerome A. and William H. Waldorf, "Multifactor Productivity: A New BLS Measure," Monthly Labor Review, December 1983, 12-15.

Marlin, James W. Jr., "Estimating Monetary Loss Due to Personal Injury," Journal of Forensic Economics, May 1988, 1(2), 1-18. 
Pelaez, Rolando F., "The Total Offset Method," Journal of Forensic Economics, April $1989,2(2), 45-60$.

Schilling, Don, "Estimating the Present Value of Future Income Losses: An Historical Simulation 1900-1982," Journal of Risk and Insurance, March 1985, 100-116. 